\title{
Importing mental patterns of coherence as a comprehension strategy: a case study of errors in reference assignment
}

\author{
Pilar Alonso
}

Departamento de Filología Inglesa, Universidad de Salamanca, Spain

https://doi.org/10.36505/ExLing-2010/03/0003/000123

\begin{abstract}
This paper addresses the interface between structural coherence, which builds on the formal and conceptual conventions of discourse, and cognitive coherence, which develops around the internal and external aspects of communication (Pasquier and Chaib-draa 2005). More specifically, the focus is on the cognitive coherence strategies set forth by discourse receivers when they encounter comprehension problems, especially those caused by non-standard uses in structural coherence. Drawing from studies on coherence and comprehension (Giora 1997; Wilson and Matsui 2000; Hobbs 2004), the paper discusses a case study which shows how error in reference assignment may encourage readers to import mental patterns of coherence, external to the discourse, as a repair strategy, thus prioritizing structural adjacency and their search for relevance over comprehension.
\end{abstract}

Key words: Coherence, comprehension, topic construction, adjacency, relevance

\section{Statement of the problem}

It is common in narrative discourse to build readers' expectations on cataphoric referential ties which open empty mental spaces to be filled later on. Thus, cataphoric reference challenges readers' expectations on topic continuity, especially when the complexity or ambiguity of the discourse makes it difficult to assign referents to some pronouns. This is precisely what happens in the passage quoted below, which is the beginning of Katherine Mansfield's short story "The Man Without a Temperament". The personal reference problem occurs at the end of the excerpt:

HE stood at the hall door turning the ring, turning the heavy signet ring upon his little finger while his glance travelled coolly, deliberately, over the round tables and basket chairs scattered about the glassed-in veranda. He pursed his lips-he might have been going to whistle-but he did not whistle-only turned the ring-turned the ring on his pink, freshly washed hands.

Over in the corner sat The Two Topknots, drinking a decoction they always drank at this hour-something whitish, greyish, in glasses, with little husks floating on the top-and rooting in a tin full of paper shavings for pieces of speckled biscuit, which they broke, dropped into the glasses and fished for with spoons. Their two coils of knitting, like two snakes, slumbered beside the tray.

ExLing 2010: Proceedings of 3rd Tutorial and Research Workshop on Experimental Linguistics, 25-27 August, Athens, Greece 
The American Woman sat where she always sat against the glass wall, in the shadow of a great creeping thing with wide open purple eyes that pressed-that flattened itself against the glass, hungrily watching her. And she knoo it was thereshe knoo it was looking at her just that way. She played up to it; she gave herself little airs. Sometimes she even pointed at it, crying: "Isn't that the most terrible thing you've ever seen! Isn't that ghoulish!" It was on the other side of the veranda, after all . . . and besides it couldn't touch her, could it, Klaymongso? She was an American Woman, wasn't she, Klaymongso, and she'd just go right away to her Consul. Klaymongso, curled in her lap, with her torn antique brocade bag, a grubby handkerchief, and a pile of letters from home on top of him, sneezed for reply.

The other tables were empty. A glance passed between the American and the Topknots. She gave a foreign little shrug; they waved an understanding biscuit. But he saw nothing. Now he was still, now from his eyes you saw he listened. "Hoo-ezip-zoo-oo!" sounded the lift. The iron cage clanged open. Light dragging steps sounded across the hall, coming towards him. A hand, like a leaf, fell on his shoulder. A soft voice said: "Let's go and sit over there-where we can see the drive. The trees are so lovely." And he moved forward with the hand still on his shoulder, and the light, dragging steps beside his. He pulled out a chair and she sank into it, slowly, leaning her head against the back, her arms falling along the sides.

At the end of the last paragraph, there are three cases of personal reference, the pronoun "she" and the possessive determiners "her" (here highlighted in bold types), which refer to an entity whose existence, at this early stage in the story, has to be inferred from the narrative. Although the character to which these personal and possessive elements refer becomes the centre of the story from then on, readers have to wait over a thousand words to identify her by name (her first name, Jinnie, is revealed after 1041 words in a 5062 words story, as part of an elusive flashback; and her family name, Mrs. Salesby, occurs even later, after 1664 words). This absence of direct reference identification causes problems in the mental operations of anchoring and distributing characters within the narrative structure, which readers automatically perform as they receive information. Thus, the delay imposed by the literary use of cataphoric reference by Mansfield in her story tends to become an obstacle to surmount during the comprehension process.

\section{Case study}

Over many years of teaching, a great number of my graduate and undergraduate students of English have shown a tendency to recurrently identify the female figure behind the quote "she sank into it, slowly, leaning her head against the back, her arms falling along the sides" with "The American Woman", the secondary character which opens the third paragraph in the story. This is a repeated, not an isolated, fact.

From a discourse-structure adjacency perspective (Hobbs 2004), the error is comprehensible, because readers' expectations make them give priority to 
proximity in their search for an identity that suits the character; and it is also understandable from a relevance point of view (Wilson and Matsui 2000), because readers' expectations are more easily, and more economically, satisfied by filling the pronoun with the closest possible matching referent. Following Giora (1997), however, both operations would be subject to the rapid identification and statement of a topic, conducive to the construction of a coherent mental model. The analysis of the situation under study actually proves, however, that local interpretive errors, such as the error in reference assignment described here, may trigger patterns of coherence which do not match the author's planned topic in the receiver's mind.

In my teaching experience, there are a significant number of students who recurrently interpret Mansfield's story along the 19th century literary pattern of the "Innocent American abroad", a topic they have studied in their literature classes. According to the imported pattern, both protagonists, Mr. And Mrs. Salesby, are a mixed-nationality couple (i.e. The English Man (Without a Temperament) and the American Woman of the story), and the conflict between them, their mixture of loving nearness and ice-cold aloofness, comes from prototypical socio-cultural differences. In this way, students construct a coherent mental model drawing inferences from a preacquired well-structured coherent model which helps them to solve the difficulties implicit in the story. But contrary to these students' interpretive and literary inferences, the problems presented in "The Man Without a Temperament" have nothing to do with cultural shock, or extravagant social behavior. In Mansfield's story, death is central, but it does not follow improper social behavior, as occurs, for instance, in Henry James' Daisy Miller, a story with which these students are familiar. In "The Man Without a Temperament", death is the personal tragedy of a woman, Mrs. Salesby, who is critically ill, and of her husband, who, being young and healthy, finds himself dramatically trapped in it.

The fact that, year after year, there are students who, disregarding the flow of information received, import a whole coherent cognitive pattern external to the discourse to satisfy their interpretive purpose, seems to imply that building a coherent mental representation of the story prevails over the need to unfold and grasp the actual topic of the story. This may indicate that: first, the search for coherence is a pre-requisite of interpretation processes, not a consequence; second, a dissociation between cognitive coherence constructs and structural coherence networks appears to cause problems in comprehension; third, coherence patterns may be borrowed from previouslyknown cognitive domains as a comprehension strategy in an attempt to repair local structural problems; and fourth, once imported, the external coherence patterns may be superimposed on the discourse model with largescale cognitive effects. Our research has shown that the divorce between linguistic antecedents, frame-oriented associations, and readers' assumptions 
may lead to filling up empty coherence spaces with coherent patterns obtained from previous knowledge or other discourse models.

Our research confirms that comprehension is, in fact, guided by the principles of early topic identification (Giora 1997), adjacency (Hobbs 2005) and relevance (Wilson and Matsui 2000); but our evidence has also made it clear that following these steps may not be sufficient for good comprehension results. The case of error in reference assignment, which has been studied here, has revealed that the search for relevance stops when a coherent mental representation of the discourse content (be it a complex mental model or a mental image) is constructed. Our research has also shown that, when there are failures in the identification of the structural components, readers may import external patterns of coherence as a comprehension-repair strategy to satisfy their need for a coherent cognitive representation. Once established, these patterns may prevail over the information received, with large scale consequences for the global reading process. This combination of factors recommends stressing the interface between cognitive coherence and structural coherence (Pasquier and Chaibdraa 2005) and their mutual role in the comprehension process.

\section{Notes}

1. Research for this article has been financed by the Junta de Castilla y León Grant SA012A09.

\section{References}

Giora, R. 1997. Discourse coherence and theory of relevance: Stumbling blocks in search of a unified theory. Journal of Pragmatics 27, 17-34.

Hobbs, J.R. 2004. Abduction in Natural Language Understanding. In Horn, L., Ward, G. (eds.), Handbook of Pragmatics. Oxford: Blackwell.

Holmes, M.S. Literature Annotations. The Man Without a Temperament. http://litmed.med.nyu.edu/Annotation?action=view\&annid=1408. 27 April 2010.

Mansfield, K. 1981. The Man Without a Temperament. In The Collected Stories of Katherine Mansfield. Harmondsworth: Penguin Books. 129-143.

Pasquier, P.,B. Chaib-draa, 2005. Agent Communication Pragmatics: The Cognitive Coherence Approach. Cognitive Systems Research, Volume 6, No 4: 364-395.

Wilson, D., Matsui, T. 2000. Recent Approaches to Bridging: Truth, Coherence, Relevance. Lengua, Discurso, Texto. Bustos Tovar, J.J. et al. (ed.) Madrid: Visor Libros. 103-31. 